\title{
Accessible Tourism in Natural Park Areas: A Social Network Analysis to Discard Barriers and Provide Information for People with Disabilities
}

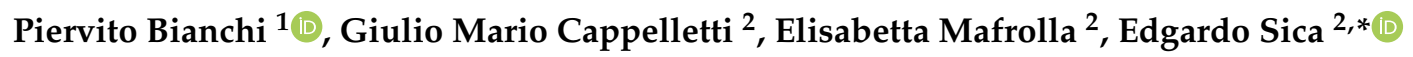 \\ and Roberta Sisto ${ }^{2}$ D \\ 1 Department of Economics, University of Foggia, 71121 Foggia, Italy; piervito.bianchi@unifg.it \\ 2 Department of Economics, Management and Territory, University of Foggia, 71121 Foggia, Italy; \\ giulio.cappelletti@unifg.it (G.M.C.); elisabetta.mafrolla@unifg.it (E.M.); roberta.sisto@unifg.it (R.S.) \\ * Correspondence: edgardo.sica@unifg.it; Tel.: +39-0881-781-711
}

Received: 5 October 2020; Accepted: 17 November 2020; Published: 27 November 2020

\begin{abstract}
Although regulations designed to meet the necessities of tourists with disabilities are allowing disables to travel more, they are still encountering barriers and discriminatory practices. A relevant obstacle in making the tourist policy effective is represented by the lack of information and communication about needs and expectations of disabled categories. In this context, the present paper focuses on the coproduction process of tourist public policies for disables by looking at the network that facilitates communication among the actors taking part in the process. We adopt the Social Network Analysis (SNA) to study the policy network, i.e., how public administrations and policy users (associations of citizens/people with disabilities and entrepreneurs) exchange information about the accessibility to the Gargano National Park, a protected natural area in the South of Italy. In particular, we investigate the role of entrepreneurial stakeholders in channeling information and the presence of policy brokers, i.e., stakeholders that spread the policies to the whole network. Our findings show that a limited number of actors involved in granting accessibility to tourists with disabilities is engaged in information exchanges. Moreover, information flows are guided by only one public administration that plays, therefore, a key role in the implementation of policies that support the parks' accessibility.
\end{abstract}

Keywords: accessible tourism; responsible tourism; natural parks; social network analysis; Gargano national park

\section{Introduction}

Woodland and wildlife experiences have long been considered unattainable practices for people with disabilities [1], marking a difference from nondisabled people [2], which should not exist in our society of equality [3]. Nevertheless, in the last two decades, research in sociological and medical studies supported the relevant benefits gained by those people that engaged in outdoor experience, although they were affected by various types of disabilities [4-7]. The achievements trespassed a passive aim of rehabilitation, as people with disabilities obtained results in terms of revitalization [8], too. Even if the implementation of regulations designed to meet the necessities of tourists with disabilities is allowing them to travel more, they still encounter barriers and discriminatory practices, which prevent them from fully exercising their rights. This topic is widely studied in the literature, both in the framework of tourist accessibility and in the context of accessibility to protected natural areas $[9,10]$.

Research has variously investigated the barriers and facilitators towards this kind of experience, finding that information is a key issue for the development of outdoor policies for people with 
disabilities [1]. Some authors [2] argue that lack of information represents one of the most relevant barriers toward the accessibility of open space areas by people with disabilities, and the opportunity to communicate needs and expectations by disabled categories has a relevant role at making the tourist policy effective. Moreover, since accessible facilities and services contribute to improve the quality of the tourism experience and can create more job opportunities for people with disabilities, accessibility represents an intrinsic part of any responsible and sustainable tourism strategy and policy [11]. At regards, it is worth noting that while sustainable tourism focuses on a long-term future objective, responsible tourism focuses on short-term actions every one of us should take to reach the future endpoint of sustainable tourism [11].

Previous studies [12-15] documented that various actors should be engaged in the production of the public policy. Hence, different kinds of stakeholders are expected to be involved in a coproduction process, which implies that policies should be programmed and enacted by public administrations together with policy users. This assumption becomes particularly relevant when dealing with individually complex systems [16], such as responsible/sustainable tourism, disability, and natural areas.

Each different category of actors involved with the accessibility of natural areas by tourists with disabilities, produces a complex knowledge that should contribute to solve the issue throughout an exchange of information regarding the public policy. However, no previous analysis focused so far on how the exchange of information among stakeholders facilitates disabled categories, and how this might impact on feasible exploitation of natural open space experiences by tourists with disabilities.

Starting from these premises, the paper focuses on the coproduction process of tourist public policies for people with disabilities by looking at the network that facilitates communication among the actors taking part in the process. More specifically, we adopt the approach of the Social Network Analysis (SNA) to study the policy network, i.e., how public administrations and policy users (associations of citizens/people with disabilities and entrepreneurs) exchange information about the accessibility of a woodlands tourist service. In particular, starting from the investigation about the existence and the basic features of the policy network, we investigate the role of entrepreneurial stakeholders in the network of information flows. Moreover, we explore the presence of those stakeholders (policy brokers) that may link different actors and construct bridges toward the less connected ones [17]. By occupying a central position within the network, these policy brokers may play the role of vehicles for spreading the policies to the whole network $[18,19]$.

We carry out our investigation by concentrating on a peculiar service, namely the people with disabilities accessibility to natural park areas, which is a tourist public service widely recognized as a priority in the European Disability Strategy 2020-2030 [20]. The study focuses, therefore, on the network among stakeholders in a protected natural area in order to investigate whether the structural characteristics of the network can foster the application of public policies aimed at improving the tourism accessibility of the area. To this end, we explore the case of the Gargano National Park, a protected natural area located in the South of Italy.

The article follows the outline described below. In Section 2, a brief theoretical overview on the role of the flows of information within the network of stakeholders and our research hypotheses are presented. In Section 3, we describe the empirical study, and in Section 4, we display and discuss results in detail. Finally, Section 5 briefly concludes the paper.

\section{Stakeholders Network and Information Exchange for Tourists with Disabilities}

Although the position of people with disabilities as open space users has been long overlooked, very little is known about tourist policies and experiences by disabled categories [1]. Indeed, previous research mainly discussed the feasible benefits and main constraints faced by people with disabilities in accessing open spaces, including woodlands. As expected, accessibility issues were discovered. Medical research listed and ranked constraints and facilitators and documented that the main barrier was lack of information, whereas appropriate information was the main facilitator: information disposes 
users' "psychological state such as personality, interests and attitude towards leisure" [2], so that disabled people feel at risk while outdoor [21], and avoid risk-taking unless properly informed [21,22].

A second key issue, in both leisure academic research and policy making for disabled people, is that the discussion and implementation of the policy is largely in the hands of nondisabled people [1], although some relevant theoretical and empirical studies documented that better outcomes could be produced only engaging people with disabilities in the policy-making process [23]. Conclusively, taking part of the policy-making process is relevant for disabled categories, as other types of nondisabled stakeholders hardly have the competences to produce an adequate policy [24].

In this paper, we investigate the information exchange among stakeholders in the process of policy coproduction to foster the accessibility of people with disabilities and promote the benefits exploitation from woodland experiences.

Public administrations have the duty to promote a public policy, but their competences in some specific fields are limited. Therefore, they would need the collaboration of different categories of stakeholders (associations of citizens/ people with disabilities and entrepreneurs) in order to produce the policy and the flows of information would be democratic, as both public administrations and users would assimilate and deliver information from the others, with no feasible hierarchy of roles.

The role of associations of citizens/people with disabilities is crucial, since disabled needs and expectations are a rather specialist and complex area of knowledge, and most of public administrations officers are nondisabled and would need the collaboration of disabled people to figure out and implement the appropriate policy. Moreover, woodlands exploitation is a specialist complex area of knowledge as well and this implies relevant environmental concerns and requires infrastructural knowledge. On the other side, disabled tourist exploitation of the woodlands is a complex topic that requires entrepreneurs to support the economic development of the area, making business in the sector of service delivery for tourism. We verify the relevance of enterprises, which could access information and use the network in order to promote their business. Indeed, this represents a precondition for a vital network of businesses to occur. Following such rationale, we predict and test the following hypotheses:

Hypotheses 1: Entrepreneurial stakeholders may easily access ideas, information, and resources, and, in general, garner opportunities and resources required for their success.

Hypotheses 2: Public administrations and policy users operate in a democratic environment, where information flows are reciprocal and nonhierarchical.

According to service theory [25], some specialized actors should be able to drive the process, because the process requires specialized knowledge, and some stakeholders possess better expertise than others. We expect that some representatives would be more relevant than others, notwithstanding the democratic basis of information flows, and, thus, predict and test a second hypothesis:

Hypotheses 3: A few public administrations guide the information flows.

As it happens in democratic contexts, there is a feasibility that some stakeholders are not that specialized to take part to the discussion actively. As long as the discussion would imply two different fields of specialization, some nodes could feel uncomfortable at delivering information in the one field in which they are not specialized, and some of the stakeholders could bear larger resources and be able to deliver a greater amount of information. Consequently, some main stakeholders would be conducting the information flows, and some others would principally collect the information given by the main stakeholders, notwithstanding their right and duty to actively take part in the co-production process. Hence, we complete $\mathrm{H} 3$, with the following subhypothesis:

Hypotheses 3.1: In the policy network some nodes are mainly spectators.

Finally, policy users could be representative of disabled categories that are geographically spread on the territory in a different way, some being relevant in a narrow area and some being relevant in a wider one. Similarly, the sociological relevance of stakeholders is varied, some of them incorporating 
the instances of a wider collection of users, some bearing the instances of a very narrow selection of users. We expect that policy users that geographically or sociologically embrace a wider portion of users, would be used by other policy users in order to more comfortably reach the public administrations. Therefore, $\mathrm{H} 3$ can be completed with the following further subhypothesis:

Hypotheses 3.2: The information exchange in the process of policy coproduction has various intensity and some policy users are employed by spectator-nodes to shorten the distance from public administrations.

\section{Results}

\subsection{The Context of Analysis}

We tested our hypotheses by investigating the case of the Gargano National Park (https://www. parcogargano.it), which is located in the Southern Italian Apulia Region and encompasses an area of approximately 120,000 hectares in the province of Foggia (Figure 1).

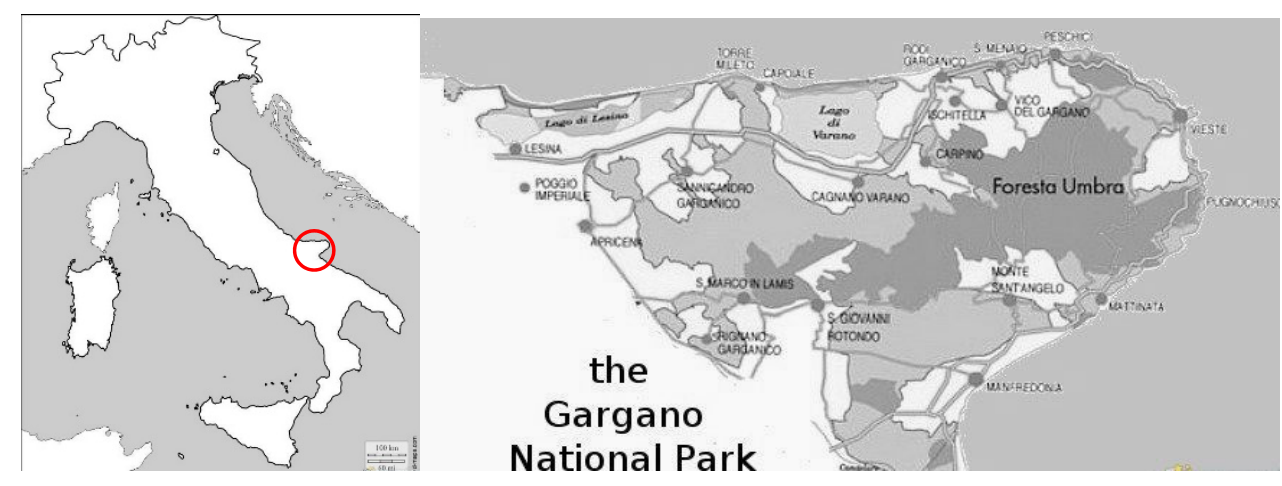

Figure 1. Location of the case study.

The Park was established in 1991 and comprises 18 municipalities with several tourist attractions, including religious and historical sites (such as those located in San Giovanni Rotondo, Monte Sant'Angelo, and Manfredonia), coastal towns (Rodi Garganico, Peschici, Vieste, and Mattinata), and protected areas (in particular, the Marine Reserve of the Tremiti Islands and the Umbra Forest, which has been a vast habitat since prehistoric times). Moreover, the Park preserves a rare concentration of different habitats, including rare flower and wildlife species. In light of this, the Gargano National Park exhibits a strong tourism potential, as confirmed by the increasing number of visitors yearly, which moved from approximately 791,000 in 2014 to 851,000 in 2018 [26].

In this framework, the possibility of providing a set of services and facilities specifically addressed to individuals with special needs, thus, guaranteeing them the full inclusiveness of the tourism supply, represents a worthwhile matter of investigation. In particular, the presence of a network in which each actor is embedded may enable entrepreneurs and users to access a specific amount of information and technical knowledge that affect both the actors' business performance and the policy adoption success.

\subsection{The Social Network Measures}

As discussed in Section 1, tourism, disability, and natural areas represent complex systems that can be fully understood only when analyzed as a whole, regardless of the number of parts they are composed of.

Complex systems can be conceived as networks of interacting elements leading to global behaviors that are not observable at the level of the single elements and that share similar characteristics [27]. Thus, in the last decades, network analysis-i.e., the set of techniques used to study the exchange of resources (goods, services, money, or information) among actors within the network-has been increasingly employed to investigate complex systems [28,29]. Indeed, the network analysis can be 
particularly useful to reveal the pattern of relationships, the availability of resources, and the exchange of resources between the actors [30].

The concept of network is not new in the field of tourism research. Some scholars [31] have summarized a number of tourism research areas that exploit the network concept. More specifically, the relevance of representing the organizational structure of tourism sector as a network of interdependent stakeholders rests on two orders of reason. Firstly, tourism stakeholders rely on the network itself to access ideas, information, and resources, and, in general, to garner opportunities and resources required for their entrepreneurial success [32]. Secondly, the network is useful to forecast the success or the failure of any policy action, by allowing to explore how the flow of information and other resources are exchanged and channeled among tourism actors [33].

Starting from these premises, we employ SNA to investigate whether the structural characteristics of the network among disability stakeholders and tourism entrepreneurs in the Gargano National Park can: (i) favor the entrepreneurial success of the latter and (ii) foster the application of public policies aimed at improving the users with disabilities accessibility of the area.

SNA is a research method largely employed in social sciences to analyze the collective properties of social systems composed of a large number of interconnected parts that are strongly influenced by the topology of the connecting network $[34,35]$.

It focuses on the networks' structural description by investigating the social context and behavior of relationships among actors rather than the rational choice that individual actors make [36]. The core unit of analysis is, of course, the social network defined as "a specific set of linkages among a defined sets of persons with the additional property that the characteristics of these linkages as a whole may be used to interpret the social behavior of the persons involved" [37]. That is, "a social network consists of a finite set or sets of actors and the relation or relations defined on them" [30]. In particular, SNA is characterized by two perspectives: the socio-centered and ego-centered perspective [38]. The socio-centered perspective concentrates on the overall network structure. It looks for patterns of ties that indicate cohesive social groups, central actors that may be paramount to the integration of the social network, and asymmetries that may reflect social prestige or social stratification. Conversely, the ego-centered perspective considers the structural properties of each single node and how single actors influence one another through their network ties.

We tested our hypotheses by adopting both the perspectives. In particular, the socio-centered approach allowed us to explore to what extent the network characteristics may foster the entrepreneurial success of stakeholders as well as the diffusion of public policies designed to enhance the tourism accessibility of the area, addressing, thus, hypotheses H1, H2, and H3.1. In contrast, by adopting the ego-centered approach we could identify the most relevant policy brokers, i.e., those actors that can mostly facilitate the application of the aforementioned policies, testing, therefore, hypotheses $\mathrm{H} 3$ and H3.2.

More specifically, to deal with hypothesis H1, we employed a wide range of quantitative measurements that allowed us to analyze the main characteristics of the network and to understand how information and knowledge flow through the network [39]. These include mainly measures of connectivity or cohesion, which relate to the extent to which subsets of actors are cohesive. In detail, a network is connected if there is a path between each pair of nodes, meaning that all pairs of nodes are reachable. We, therefore, explored the actors' connectivity in terms of network's density, average degree, centralization, and geodesic distance. Indeed, different levels of connectivity may have distinct impacts on how information, knowledge, and innovation may flow within the network and reach all actors [30]. For instance, lower distance and reachability can facilitate the diffusion of innovations and information, increasing the level of trust, homogeneity, and strength of relations. Similarly, we tested hypothesis $\mathrm{H} 2$ by checking for the network's reciprocity, i.e., the likelihood of vertices to be mutually linked, and hypothesis $\mathrm{H} 3.1$ by calculating the nodes' peripherality that provides information about those nodes that act only as spectators. Finally, concerning hypotheses H3 and H3.2, we followed most of the empirical studies on brokerage $[18,19,40]$ by identifying brokerage positions through the 
betweenness centrality index. Indeed, the more an actor is between other vertices, the more it may contribute to spread policies within the network [41]. Moreover, centrality has implications for power, not only due to the access and control of information, but also in what relates to the access to alternative actors in the network, reducing the dependence over one or few network nodes [42]. More specifically, we firstly calculated the betweenness centrality for the whole network and then for each category of stakeholders (public administrations and policy users), selecting those actors with the highest scores (i.e., those included in the 1st quartile). In this way, we could identify the public administrations that may guide the information flows (hypothesis H3) as well as the policy users that can be adopted to shorten the distance from public administrations (hypothesis H3.2). Table 1 reports the detailed description of the SNA indexes adopted with the corresponding hypotheses addressed.

\subsection{Sample and Data Collection}

The analysis was carried out by using data collected from an ad hoc designed questionnaire that was addressed both to the most relevant actors involved in tourism activities (public administrations and entrepreneurs) within the Gargano National Park and to the representatives from the main disability associations. The questionnaire was structured in two parts. The first was aimed at gathering general information on the respondent's characteristics; the second collected information on their relations and, more precisely, on the existence or not of ties among actors in terms of (i) any kind of interaction, (ii) exchange of general information and knowledge, and (iii) technical collaborations. Accordingly, we were able to gather three different networks, namely:

1. the interaction network;

2. the communication network;

3. the technical network.

The first network describes the relational structure connecting the actors who had a generic interaction. The communication network is more specific since it includes information and knowledge exchanges specifically related to production, market, law system, etc. Finally, within the communication ties, only those relations characterized by a real exchange of technical knowledge (i.e., information exchange that can directly affect the firm's productivity) composed the technical network. 
Table 1. Social Network Analysis (SNA) indexes employed in the empirical analysis.

\begin{tabular}{|c|c|c|c|}
\hline Index & Description & Measure & $\begin{array}{l}\text { Hypothesis } \\
\text { Addressed }\end{array}$ \\
\hline Density & $\begin{array}{l}\text { How many ties between actors exist compared to how many ties between } \\
\text { actors are possible [43]. The more points that are connected, the higher the } \\
\text { density the graph presents. }\end{array}$ & $\begin{array}{l}\text { Number of edges/Total } \\
\text { possible number of edges }\end{array}$ & \multirow{4}{*}{7} \\
\hline $\begin{array}{l}\text { Average } \\
\text { degree }\end{array}$ & Average number of edges per node in the graph [44]. & Total Edges/Total Nodes & \\
\hline $\begin{array}{l}\text { Network } \\
\text { centralization }\end{array}$ & Overall integration of the graph (and not relative prominence of points) [45]. & $\begin{array}{c}C^{d}=\frac{\sum_{i}\left[c^{d *}-c_{i}^{d}\right]}{\max _{y} \sum_{i}\left[c^{*}-c_{i}^{d}\right]} \\
\text { where: } \\
c_{i}^{d}=\text { actor centrality } \\
c^{d *}=\text { maximum actor } \\
\text { centrality observed in } \\
\text { the network } \\
\sum_{i}\left[c^{d *}-c_{i}^{d}\right]=\text { sum of } \\
\text { differences between most } \\
\text { central actor and others } \\
C^{d}=0 \text { if all units have equal } \\
\text { centrality value; }=1 \text { if one unit } \\
\text { completely dominates all } \\
\text { other units }\end{array}$ & \\
\hline $\begin{array}{l}\text { Geodesic } \\
\text { distance }\end{array}$ & $\begin{array}{l}\text { Number of relations in the shortest possible walk from one actor to another } \\
\text { and, hence, efficiency of the information flow within the network [44]. }\end{array}$ & $\begin{array}{l}\text { Number of possible edges in a } \\
\text { network comprising } n \text { nodes. }\end{array}$ & \\
\hline $\begin{array}{l}\text { Hybrid } \\
\text { Reciprocity }\end{array}$ & $\begin{array}{l}\text { A tie is reciprocated if whenever a tie is connected from actor A to actor B then } \\
\text { there is a tie from actor B to actor A. }\end{array}$ & $\begin{array}{l}\text { Number of reciprocated } \\
\text { dyads/Number of } \\
\text { adjacent dyads. }\end{array}$ & \multirow{2}{*}{ - $\mathrm{H} 2$} \\
\hline $\begin{array}{c}\text { Arc } \\
\text { Reciprocity }\end{array}$ & $\begin{array}{l}\text { An arc (i.e., an ordered pair }(x, y) \text { where } x \text { sends a tie to } y) \text { is said to be } \\
\text { reciprocated if the } \operatorname{arc}(y, x) \text { is also present. }\end{array}$ & $\begin{array}{l}\text { Number of reciprocated } \\
\text { arcs/Total number of arcs. }\end{array}$ & \\
\hline Peripherality & $\begin{array}{l}\text { Converse of centrality. It captures actors that are not isolated but are poorly } \\
\text { integrated into their network and, therefore, are likely to have limited } \\
\text { influence and to be uninvolved in communication flows within the network. }\end{array}$ & $\begin{array}{l}\text { Visual inspection of } \\
\text { the sociogram. }\end{array}$ & H3.1 \\
\hline
\end{tabular}


Table 1. Cont

\begin{tabular}{|c|c|c|c|}
\hline Index & Description & Measure & $\begin{array}{l}\text { Hypothesis } \\
\text { Addressed }\end{array}$ \\
\hline $\begin{array}{c}\text { Betweenness } \\
\text { centrality }\end{array}$ & $\begin{array}{l}\text { Number of times a node lies on the shortest path between other nodes, } \\
\text { showing thus, which nodes are "bridges" between nodes in a network. In a } \\
\text { communication network, therefore, this measure identifies the individuals } \\
\text { who influence the information flow around a network: a high betweenness } \\
\text { count could indicate someone holds authority over disparate clusters in a } \\
\text { network, or just that they are on the periphery of both clusters. }\end{array}$ & $\begin{array}{l}C_{B}\left(n_{i}\right)=\sum_{j<k} g_{j k\left(n_{i}\right)} / g_{j k} \\
\text { where } g_{j k}=\text { number of } \\
\text { geodesic (shortest paths) } \\
\text { connecting } j k \text {, and } g_{j k}\left(n_{i}\right)=\text { the } \\
\text { number that node } i \text { is on. }\end{array}$ & $-\begin{array}{l}\text { H3 } \\
\text { H3.2 }\end{array}$ \\
\hline
\end{tabular}


Respondents were identified on the basis of secondary data (blogs, websites, brochures, reports, etc.). The initial list of actors was composed of 28 units. Subsequently, we augmented the number of units in the original sample by following a free recall approach. By means of this technique, respondents were asked to name those actors with whom they had a relation without referring to a fixed list [46]. Hence, we included in the sample those actors that were mentioned as link by any actor originally included in the target sample. This list also includes some relevant actors external to the Gargano National Park because, from a dynamical perspective, the absence of external relations could cause the death of the system due to its small innovative capability [47]. The final list of network actors was, therefore, composed of 49 units: 12 public administrations and 37 policy users.

In order to obtain the "roster of observable actors", the questionnaire was administrated in April and June 2019 during two different focus groups that we organized to define a trademark specification to improve disabled tourists' accessibility to the Park. On the whole, we obtained 28 fully answered questionnaires, namely 21 from the first focus group and 7 from the second.

\section{Results and Discussion}

The networks were analyzed using the software toolkit UCINET 6.0 [48]. Below we report, for each hypothesis, the results obtained.

\section{- Hypothesis H1: not verified}

As discussed in Section 2, the basic hypothesis is that the network structure enables and supports the entrepreneurial success. This occurs both through simple interaction relationships and through exchange relationships of generic or even more specific knowledge (communication and technical network, respectively). Table 2 reports, therefore, the actors' connectivity in terms of density, average degree, centralization, and geodesic distance for all the networks analyzed.

Table 2. Actors' connectivity by type of network.

\begin{tabular}{cccc}
\hline Index & Interaction Network & Communication Network & Technical Network \\
\hline Density & 0.218 & 0.098 & 0.025 \\
Average degree & 10.449 & 4.694 & 1.204 \\
Network centralization & $31.59 \%$ & $29.66 \%$ & $16.83 \%$ \\
Geodesic distance & 1.916 & 2.462 & 3.621 \\
\hline \multicolumn{4}{c}{}
\end{tabular}

Source: our elaboration based on data from direct survey.

Looking at the network properties, we can observe that the number of undirected relations decreases moving from the interactions to the technical network and, as consequence, it results in a lower density. This is consistent with the findings achieved in other studies [33,49], suggesting that only few of the local actors involved in granting accessibility to tourists with disabilities are currently engaged in information and knowledge exchanges. Indeed, when knowledge exchange and technical collaboration are taken into account, the network properties get worse and this may be curbed by organizing events with the aim to improve the strength of relations and, consequently, flow and exchange of knowledge and technical information.

- Hypothesis H2: partially verified

Results achieved from reciprocity indexes are reported in Table 3.

Table 3. Actors' reciprocity by type of network.

\begin{tabular}{cccc}
\hline Index & Interaction Network & Communication Network & Technical Network \\
\hline Hybrid Reciprocity & 0.949 & 0.984 & 0.686 \\
Arc Reciprocity & 0.974 & 0.992 & 0.814 \\
\hline
\end{tabular}

Source: our elaboration based on data from direct survey. 
Moving from the interaction to the communication network, the likelihood of actors to be mutually linked improves. This means that the network in which public administrations and policy users operate is quite democratic, without a strong hierarchy. However, these properties get worse moving to the technical network, where there are two actors that are significantly central and that, therefore, hold a kind of power. This can be observed by the visual inspection of the sociograms used to address the hypothesis H3.1 and reported later in the section.

- Hypothesis H3: verified

The identification of policy brokers to address the hypothesis H3 has been specifically carried out on the interaction network with the aim of identifying those actors who can spread any kind of information to the other stakeholders due to their great number of relationships. By occupying a relevant position within the network, indeed policy brokers may play the role of vehicles for spreading the positive consequences of policies to the whole network by linking different actors and constructing bridges toward the less connected ones. Table 4 reports, therefore, the list of actors with the highest betweenness centrality included in the 1st quartile (13 actors), organized by type of stakeholder (public administrations or policy users).

Table 4. Betweenness centrality by type of stakeholder.

\begin{tabular}{ccc}
\hline Betweenness Centrality Score & Actor No. & Public Administrations (PA) / Policy Users (PU) \\
\hline 742.06 & 36 & PA \\
189.69 & 31 & PU \\
140.43 & 35 & PA \\
133.27 & 7 & PU \\
129.52 & 47 & PA \\
120.51 & 33 & PU \\
89.56 & 3 & PA \\
81.65 & 5 & PA \\
76.77 & 2 & PA \\
60.88 & 29 & PA \\
48.11 & 1 & PA \\
41.18 & 34 & PU \\
39.99 & 20 & PU \\
\hline
\end{tabular}

Source: our elaboration based on data from direct survey.

From the Table 4, it emerges that most of policy brokers (8 out of 13) are public administrations whereas only 5 belong to the category of policy users, i.e., the whole of citizen organizations, volunteers, people outside any organization or government, etc. In particular, a relevant finding arises from the brokerage role played by the actor no. 36 (Pugliapromozione-the Regional Tourism Agency entrusted with the management and promotion of the tourist destination of the Apulia Region), whose betweenness centrality score is approximately 4 times higher compared to the second actor in the list (742.06 versus 189.69). This suggests the fundamental role that this broker plays in the effective implementation of tailored policies to support the tourism accessibility of the area and confirms the $\mathrm{H} 3$ hypothesis according to which the information flows within the network are guided by a few (in our case only one) public administrations.

- Hypothesis H3.1: verified

The analysis of nodes' peripherality has been conducted through the visual inspection of the sociograms for all the networks considered (Figure 2). 


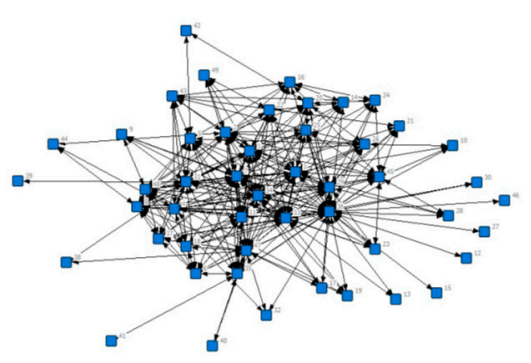

(a)

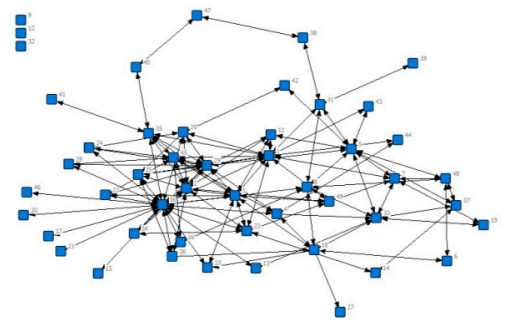

(b)

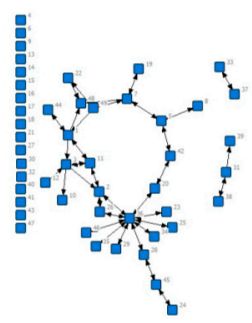

(c)

Figure 2. The policy network environment related to H3.1. (a) Interaction network, (b) Communication network (c) Technical network. Source: our elaboration based on data from direct survey.

Looking at the sociograms, it is very clear that the network become less dense and more disconnected moving from the interaction to the technical network. In particular, the technical network exhibits 17 actors completely isolated, some of them with a dyadic relationship whereas others occupying a very peripheral position in the network. Overall, therefore, the knowledge exchange in the process has various intensity and some nodes are mainly spectators.

\section{- Hypothesis H3.2: partially verified}

Table 4 reported above shows that the most relevant broker among the policy users is represented by actor no. 31, an association that provides hospital care and training for volunteers. Despite the limited number of policy users able to carry out a brokerage role, our findings seem to be partially supportive of the H3.2 hypothesis according to which some policy users can still be used by spectator-nodes to shorten the distance from public administrations. Authors should discuss the results and how they can be interpreted in perspective of previous studies and of the working hypotheses. The findings and their implications should be discussed in the broadest context possible. Future research directions may also be highlighted.

\section{Concluding Remarks}

The analysis carried out in this paper has shown that only a limited number of actors involved in granting accessibility to tourists with disabilities is engaged in information exchanges. Although the network does not exhibit a strong hierarchy among stakeholders, the knowledge exchange has various intensity and some nodes are mainly spectators. Moreover, the study suggests that the information flow within the network is guided by only one public administration that, therefore, plays a crucial role in the effective implementation of tailored policies to support the tourism accessibility of the area under investigation. However, some policy users can still be exploited to shorten the distance from public administrations. As argued in the literature discussed in the introductory section, sharing knowledge is a precondition to optimise the tourism experience of people with disabilities and the limited circulation of information represents one of the most relevant barriers towards the accessibility of open space areas. In this perspective, our findings seem to suggest that the investigated network is not completely mature to make the tourist policy effective. Indeed, results reveal the existence of a not fully cohesive network, which represents a necessary (although not sufficient) condition to encourage flows of tacit knowledge in the surrounding environment. Moreover, the presence of only one public administration guiding the information flow within the network confirms that the policy discussion and implementation is still predominantly in the hands of nondisabled people, as argued in the leisure academic research. Nevertheless, the hierarchy between public administrations and policy users is not particularly marked. This means that there is space for the full involvement of disabled categories in policies design and to give them the opportunity to communicate needs and expectations for making the tourist policy more effective. Reducing network asymmetries implies the further involvement of policy users in 
the process of policy discussion and implementation, by establishing new ties with spectators-nodes and reinforcing the existing ones. The fostering of knowledge diffusion should need the setting of a policy agenda able to encourage knowledge creation and enable sharing patterns among stakeholders. This can occur through the inclusion of policy users at every stage of the policy cycle: from the analysis of the problems to be resolved, to the policy design, implementation, monitoring, and evaluation of the results attained. To this end, engagement methods may include face-to-face forums, interviews, discussion groups, and satisfaction surveys to ensure that people with disabilities may have a significant voice in the coproduction process of tourist public policies for disables.

It is worth noting that one of the limitations of the study concerns the datasets that do not show the network dynamics or the evolution of its structure. Indeed, the data provide one picture of the current social network, reflecting the whole process. However, the snowballing method combined with a network approach might have some limitations as the impossibility of locating isolated actors. Actually, this weakness is not considered to affect or weaken the final results of this study because the theoretical assumptions concerning the nature of the network ensures that the relevant unit of analysis will be connected and not isolated. It is assumed that all relevant actors will be identified by other actors and thereby connected by a link. Consequently, unconnected actors have not really participated in any of the organizing functions and are, therefore, not to be regarded as actors in the process of policy-making.

Author Contributions: All authors have contributed equally to this work and have read and agreed to the published version of the manuscript.

Funding: This research was funded by the "E-Parks - Environmental and Administrative Knowledge Networks for a Better Tourist Attractiveness in Protected Natural Areas" research project-Interreg V-A Greece-Italy Programme, MIS CODE 5003237.

Conflicts of Interest: The authors declare no conflict of interest.

\section{References}

1. Burns, N.; Paterson, K.; Watson, N. An inclusive outdoors? Disabled people's experiences of countryside leisure services. Leis. Stud. 2019, 28, 403-417. [CrossRef]

2. Aitchison, C. Exclusive discourses: Leisure studies and disability. Leis. Stud. 2019, 28, 375-386. [CrossRef]

3. EUR-Lex. Equality and Non-Discrimination in an Enlarged European Union. 2004. Available online: https://eur-lex.europa.eu/legal-content/EN/TXT/?uri=LEGISSUM\%3Al14157 (accessed on 14 July 2019).

4. Duncan, F. Nature's prozac-The long term view. Countrys. Recreat. 2005, 13, 13-15.

5. Kaplan, S. The restorative benefits of nature: Toward an integrative framework. J. Environ. Psychol. 1995, 15, 169-182. [CrossRef]

6. Pretty, J.; Griffin, M.; Peacock, J.; Hine, R.; Sellens, M.; South, N. A Countryside for Health and Well-Being: The Physical and Mental Health Benefits of Green Exercise (Report for the Countryside Recreation Network); Countryside Recreation Network: Sheffield, UK, 2005.

7. Rhode, C.; Kendle, A. Human Well-Being, Natural Landscapes and Wildife in Urban Areas: A Review; English Nature Science Report No. 22; English Nature: Peterborough, UK, 1994.

8. Mind. Ecotherapy: A Green Agenda for Mental Health; Mind Inc.: London, UK, 2007.

9. Dimou, I.; Velissariou, E. Tourism and Accessibility. A satisfaction survey on tourists with disabilities in the Island of Crete, Conference Paper. In Proceedings of the 11th Management of Innovative Business, Education \& Support systems Conference, Heraklion, Greece, 20-22 June 2016.

10. Darcy, S.; Taylor, T.; Dwyer, L.; Cameron, B. Understanding the Notion of Accessible Spaces and Places: Sydney CBD Visitor Accessibility Web Portal www.SydneyforAll.com. Australas. Parks Leis. 2008, 22, 28-34.

11. UNWTO. Manual on Accessible Tourism for All: Principles, Tools and Best Practices, UNWTO Publications. 2016. Available online: https://www.e-unwto.org/doi/pdf/10.18111/9789284418077 (accessed on 23 October 2020).

12. Rhodes, R.A.W. Policy networks: A British perspective. J. Theor. Politics 1990, 2, 292-317. [CrossRef]

13. Lemke, A.A.; Harris-Wai, J.N. Stakeholder engagement in policy development: Challenges and opportunities for human genomics. Genet Med. 2015, 17, 949-957. [CrossRef] [PubMed] 
14. Helbig, N.; Dawes, S.; Dzhusupova, Z.; Klievink, B.; Mkude, C. Stakeholder engagement in policy development: Observations and lessons from international experience. In Policy Practice and Digital Science-Integrating Complex Systems, Social Simulation and Public Administration in Policy Research; Janssen, M., Wimmer, M.A., Deljoo, A., Eds.; Springer International Publishing: Cham, Switzerland, 2015; pp. 1-24.

15. Hutahaean, M. The Importance of Stakeholders Approach in Public Policy Making. In Proceedings of the International Conference on Ethics in Governance (ICONEG 2016), Makassar, Indonesia, 9-20 December 2016.

16. Kickert, W.J.M.; Klijn, E.H.; Koppenjan, J.F.M. Managing Complex Networks. Strategies for the Public Sector; Sage: London, UK, 1997.

17. Provan, K.G.; Kenis, P. Modes of network governance: Structure, management, and effectiveness. J. Public Adm. Res. Theory 2008, 2, 229-252. [CrossRef]

18. Burt, R.S. Brokerage and Closure: An Introduction to Social Capital; Oxford University Press: Oxford, UK, 2005.

19. Howlett, M.; Mukherjee, I.; Koppenjan, J. Policy learning and policy networks in theory and practice: The role of policy brokers in the Indonesian biodiesel policy network. Policy Soc. 2017. [CrossRef]

20. European Parliament. European Disability Strategy 2020-2030. 2020. Available online: https://multimedia. europarl.europa.eu/it/european-disability-strategy-2020-2030_15206_pk (accessed on 12 July 2020).

21. Burns, N.; Watson, N.; Paterson, K. Risky bodies in risky spaces: Disabled people's pursuit of outdoor leisure. Disabil. Soc. 2013, 28, 1059-1073. [CrossRef]

22. Hemingway, L. Taking a risk? The mortgage industry and perceptions of disabled people. Disabil. Soc. 2020, 25, 75-87. [CrossRef]

23. Osborne, S.P.; Radnor, Z.; Strokosch, K. Co-Production and the Co-Creation of Value in Public Services: A suitable case for treatment? Public Manag. Rev. 2016, 18, 639-653. [CrossRef]

24. Pestoff, V. Citizens and co-production of welfare services. Public Manag. Rev. 2006, 8, 503-519. [CrossRef]

25. Alam, I. Removing the fuzziness from the fuzzy front-end of service innovations through consumer interactions. Ind. Mark. Manag. 2006, 35, 468-548. [CrossRef]

26. Pugliapromozione-Agenzia Regionale del Turismo (2019): Osservatorio Regionale.2019. Available online: https://www.agenziapugliapromozione.it/portal/osservatorio-del-turismo (accessed on 10 July 2019).

27. Baggio, R.; Scott, N.; Cooper, C. Network Science-A Review Focused on Tourism. Ann. Tour. Res. 2010, 37, 802-827. [CrossRef]

28. Cen-Ying, L.; Heap-Yih, C.; Pin-Chao, L.; Xiangyu, W. Critical Review of Social Network Analysis Applications in Complex Project Management. J. Mark. Manag. 2018, 34, 12.

29. De Brún, A.; McAuliffe, E. Social Network Analysis as a Methodological Approach to Explore Health Systems: A Case Study Exploring Support among Senior Managers/Executives in a Hospital Network. Int. J. Environ. Res. Public Health 2018, 15, 511. [CrossRef]

30. Wasserman, S.; Faust, K. Social Network Analysis. Methods and Applications; Cambridge University Press: Cambridge, UK, 1994.

31. Scott, N.; Baggio, R.; Cooper, C. Network Analysis and Tourism: From Theory to Practice; Channel View Publications Clevedon: Somerset, UK, 1998.

32. Birendra, K.C.; Morais, D.B.; Peterson, M.; Seekamp, E.; Smith, J.W. Social network analysis of wildlife tourism microentrepreneurial network. Tour. Hosp. Res. 2019, 19, 158-169.

33. Cooper, C.; Scott, N.; Baggio, R. Network Position and Perceptions of Destination Stakeholder Importance. Anatolia 2009, 20, 33-45. [CrossRef]

34. Morone, P.; Sisto, R.; Taylor, R. Knowledge Diffusion and Networking in the Organic Production Sector: A Case Study. Eurochoices 2006, 5, 40-46. [CrossRef]

35. Pappalardo, G.; Sisto, R.; Pecorino, B. Is the partnership governance able to promote endogenous rural development? A preliminary assessment under the Adaptive Co-management approach. Eur. Countrys. 2012, 10, 543-565. [CrossRef]

36. Durland, M.; Fredericks, K. An Introduction to Social Network Analysis. In Social Network Analysis in Program Evaluation; Durland, M., Fredericks, K., Eds.; New Direction of Evaluation, No.107; John Wiley \& Sons, Inc.: Hoboken, NJ, USA, 2018.

37. Mitchell, J.C. The concept and Use of Social Network. In Social Networks in Urban Situations; Mitchell, J.C., Ed.; Manchester University Press: Manchester, UK, 1969. 
38. Conway, S.; Jones, O.; Steward, F. Realising The Potential Of The Network Perspective. In 'Social Interaction and Organisational Change: Aston Perspectives on Innovation Networks'; Jones, O., Conway, S., Steward, F., Eds.; Imperial College Press: London, UK, 2010.

39. Scott, J. Social Network Analysis: A Handbook; Sage Publications Ltd.: London, UK, 2012.

40. Esteve Del Valle, M.; Borge Bravo, R. Leaders or Brokers? Potential Influencers in Online Parliamentary Networks; Policy Internet: Wiley Periodicals, NJ, USA, 2018.

41. Everett, M.G.; Valente, T.W. Bridging, Brokerage and betweenness. Soc. Netw. 2016, 44, 202-208. [CrossRef] [PubMed]

42. Brandão, F.; Costa, C.; Buhalis, D. Tourism innovation networks: A regional approach. Eur. J. Tour. Res. 2017, $18,33-56$.

43. Brass, D. A Social Network Perspective on Human Resources Management; Oxford University Press: New York, NY, USA, 1995.

44. Tabassum, S.; Pereira, F.; Fernandes, S.; Gama, J. Social Network Analysis: An Overview. Wires Data Min Knowl. Discov. 2018, 8. [CrossRef]

45. Freeman, L. Centrality in social networks conceptual clarification. Soc. Netw. 1997, 1, 215-239. [CrossRef]

46. Ferligoj, A.; Hlebec, V. Evaluation of social network measurement instruments. Soc. Netw. 1999, 21, 111-130. [CrossRef]

47. Bramanti, A.; Senn, L. Innovation, firm and milieu: A dynamic and cyclic approach'. In Innovation Networks; Camagni, R., Ed.; Spatial Perspectives; Belhaven Press: London, UK, 2018; pp. 89-104.

48. Borgatti, S.P.; Everett, M.G.; Freeman, L.C. UCINET 5 for Windows: Software for Social Network Analysis; Analytic Technologies: Harvard, MA, USA, 2019.

49. Morone, P.; Sisto, R.; Taylor, R. Knowledge diffusion and geographical proximity: A multirelational networks approach. Open Agric. 2019, 4, 129-138. [CrossRef]

Publisher's Note: MDPI stays neutral with regard to jurisdictional claims in published maps and institutional affiliations. 